\title{
Computed tomography in the assessment of aneurysmal subarachnoid haemorrhage for clinical outcome: an observational cohort study
}

\section{David Couret}

Universite de la Reunion

\section{Salah Boussen}

Aix-Marseille Universite

\section{Dan Cardoso}

Aix-Marseille Universite

\section{Audrey Alonzo}

Universite de Toulon

\section{Sylvain Madec}

Assistance Publique Hopitaux de Marseille

\section{Anthony Reyre}

Assistance Publique Hopitaux de Marseille

Hervé Brunel

Assistance Publique Hopitaux de Marseille

\section{Nadine Girard}

Assistance Publique Hopitaux de Marseille

Thomas Graillon

Assistance Publique Hopitaux de Marseille

Henry Dufour

Assistance Publique Hopitaux de Marseille

Nicolas Bruder

Assistance Publique Hopitaux de Marseille

Pierre Simeone

Institut de Neurosciences de la Timone

\section{Olivier Meilhac}

Universite de la Reunion

Lionel J Velly ( $\sim$ lionel.velly@ap-hm.fr )

Assistance Publique Hopitaux de Marseille https://orcid.org/0000-0001-5009-1711 
Keywords: Fisher scale, subarachnoid haemorrhage, cerebral infarction, vasospasm

Posted Date: February 17th, 2020

DOI: https://doi.org/10.21203/rs.2.23767/v1

License: (c) (1) This work is licensed under a Creative Commons Attribution 4.0 International License. Read Full License 


\section{Abstract}

Background: Aneurysmal subarachnoid haemorrhage (aSAH) is a life-threatening event with major complications such as delayed cerebral infarction (DCl) or acute hydrocephalus and poor neurological outcome. $\mathrm{DCl}$ occurs most frequently 7 days after aSAH and can last for a prolonged period. The ability to predict these complications would allow the neuro-intensivist to identify patients at risk and select the most appropriate unit for hospitalization.

Methods: A 3-year single-centre retrospective cohort study was conducted in our neuroscience critical care unit. Initial computed tomography (CT) scans in patients hospitalized for aSAH were blindly assessed using eight grading systems: the Fisher scale, modified Fisher scale, Barrow Neurological Institute scale, Hijdra scale, Intraventricular Haemorrhage (IVH) score, Graeb score, and LeRoux score. We evaluated and compared these radiological scales for the early prediction of $\mathrm{DCl}$, acute hydrocephalus, and poor neurological outcome at 3 months.

Results: Of 200 patients with aSAH who survived to day 7 and were included for $\mathrm{DCl}$ analysis, $39 \%$ cases were complicated with $\mathrm{DCl}$. The Hijdra scale was the best predictor for $\mathrm{DCl}$, with a receiver operating characteristic area under the curve (ROCAUC) of 0.80 (95\% confidence interval [CI], 0.74-0.85). The ideal cut-off score for all patients was $20 / 42$, with a sensitivity of $85 \%(95 \% \mathrm{Cl}, 75 \%-94 \%)$ and specificity of $63 \%(95 \% \mathrm{Cl}, 54 \%-71 \%)$. The IVH score was the most effective grading system for predicting acute hydrocephalus, with a ROC AUC of $0.85(95 \% \mathrm{Cl}, 0.79-0.89)$. In multivariate analysis, the Hijdra scale was the only independent predictor of the occurrence of $\mathrm{DCl}$ (hazard ratio, 1.18; 95\% $\mathrm{Cl}, 1.10-1.27$ ).

Conclusions: Although these results have yet to be prospectively confirmed, our findings suggest that the Hijdra scale may be a good predictor of $\mathrm{DCl}$ and could be useful in daily clinical practice.

\section{Background}

Aneurysmal subarachnoid haemorrhage (aSAH) is a life-threatening event. Severe complications can occur after the aneurysm is secured, such as delayed cerebral ischemia $(\mathrm{DCl})$ or acute hydrocephalus requiring intensive care monitoring for 12-21 days after aSAH [1, 2]. The management of these complications in high-volume hospitals with neurosurgical and endovascular services seems to be associated with better outcome [3]. However, specialized hospitals have limited capacity in terms of neurocritical care unit beds. Optimizing resource allocation requires the ability to select patients at high risk of complications after aSAH. In this context, a radiological score that would be predictive of complications would be useful for identifying patients who need intensive care unit (ICU) monitoring.

Since the early 1980s and publication of the Fisher grade, the occurrence of vasospasm and prognosis with aSAH have been recognized as being influenced by the severity of the initial bleeding, which can be evaluated on an early computed tomography (CT) scan [4-12]. However, several studies demonstrated low sensitivity and specificity of this scale for predicting $D C I$ [6-10]. Recently, a systematic review assessing the association of radiological scales for grading aSAH with $\mathrm{DCl}$ showed that patients with 
Fisher grade 4 have a significantly lower risk of $\mathrm{DCl}$ compared to those with Fisher grade 3 [13]. With current clinical management including nimodipine, hypertensive therapy, and endovascular treatment, the Fisher grade predicts symptomatic vasospasm in only half of cases [14]. For this reason, other radiological scales have been developed to assess the amount of blood present in the subarachnoid spaces [7-10]. These scales qualitatively divide aSAH into categories, as do the Claassen scale [7] and the modified Fisher grade [9], or involve a semi-quantitative assessment, as do the Hijdra [8] or the Barrow Neurological Institute (BNI) [10] grading scales. Other grading systems, including the Graeb [15] or Leroux scales [16], or the IntraVentricular Haemorrhage (IVH) score [17], use a semi-quantitative method to assess the amount of blood present in the ventricles.

The goal of this study was to evaluate eight radiological scales in grading subarachnoid or ventricular haemorrhage or both for predicting $\mathrm{DCl}$, acute hydrocephalus, and functional outcome at 3 months in a large aSAH population.

\section{Methods}

Guidelines for reporting this study were derived from the Strengthening the Reporting of Observational Studies in Epidemiology (STROBE) Statement [18].

\section{Study design and population}

This was a single-centre retrospective cohort study of consecutive patients with an aSAH admitted during a 33-month period (January 1, 2013 to July 30, 2016) at our neuroscience critical care unit (NCCU). Access to health information was approved by an ethics committee (Comité d'éthique pour la recherche en Anesthésie-Réanimation - IRB 000102542019081), which waived the requirement for individual consent according to French law at the time of the study [19]. Inclusion criteria were age older than 18 years, an available head CT scan demonstrating aSAH prior to any neurosurgical intervention (external ventricular drainage (EVD), aneurysm clipping, or endovascular treatment), and confirmed ruptured aneurysm on subsequent digital subtraction angiography. Exclusion criteria were the presence of nonaneurysmal vascular malformations and of intracranial artefacts (prior embolization or aneurysm clipping). Patients with SAH from other causes such as head injury, arteriovenous malformation, or arterial dissection or without aneurysms confirmed on CT or angiography were excluded. Patients for whom an initial CT could not be retrieved, with incomplete CT, or with an initial CT obtained more than 24 hours after bleeding were also excluded.

\section{Clinical management}

Our aSAH management policy has been described previously in detail [1]. Briefly, all patients were managed in a dedicated NCCU according to a standardized aSAH protocol in accordance with published European guidelines [20]: administration of intravenous nimodipine and ventricular drainage in cases of hydrocephalus allowing continuous monitoring of intracranial pressure. All aneurysms were secured within 24 hours after admission with endovascular coil embolization or surgery. All patients were 
followed with transcranial Doppler sonography. Those with neurological symptoms deemed suspicious for vasospasm underwent CT angiography, followed by conventional angiography in case of moderate or severe vasospasm.

\section{CT grading}

For each patient, two independent clinicians blinded to clinical data reviewed the initial 32-slice CT scans. Each head CT was graded according to eight grading systems: the Fisher grade [4], modified Fisher grade [9], Claassen scale [7], Hijdra scale [8], BNI scale [10], Graeb scale [15], LeRoux scale [16], and IVH score [17]. Each grading system is detailed in Additional file 1 (Table S1), and an illustrative example of patient evaluation is depicted in Fig. 1.

\section{Data collection, $\mathrm{DCl}$ definition, and outcome assessment}

Data corresponding to clinical characteristics such as age, sex, the Glasgow Coma Scale [21], and the World Federation of Neurosurgical Societies (WFNS) scale [22] were recorded at admission. The Simplified Acute Physiology Score 2 (SAPS II) [23] was calculated within 24 hours after NCCU admission.

Based on the latest recommendations [24, 25], DCl was defined as follows: development of focal neurologic signs; reduction by at least 2 points on the Glasgow Coma Scale that lasts for at least one hour and is associated with angiographic cerebral vasospasm, detected either with CT angiography or digital subtraction angiography; or a new cerebral infarction detected on a CT scan, either within 6 weeks after an aSAH or before discharge, after excluding a procedure-related infarction.

Acute hydrocephalus was defined as the need to place an EVD within the first 72 hours.

Outcome was evaluated at 3 months after the bleeding using the Glasgow Outcome Scale Extended (GOSE), and dichotomized into poor (GOSE 1-4) and good outcomes (GOSE 5-8) [26].

\section{Statistical analysis}

Means and standard deviations were calculated for continuous variables with normal distributions, and medians and interquartile ranges for non-continuous variables. For categorical variables, numbers and percentages were used. Comparison between continuous variables from two groups was assessed by an unpaired two-sample t-test (normally distributed) or a Wilcoxon-Mann-Whitney $U$ test (no assumption for distribution). Differences between categorical variables were assessed by Fisher's exact test. A receiver operating characteristic $(\mathrm{ROC})$ curve was plotted to determine the ROC area under the curve $\left(\mathrm{ROC}_{\mathrm{AUC}}\right)$ and the optimal cut-off value of grading scales that best predicted $\mathrm{DCl}$, early hydrocephalus requiring EVD, poor outcome, and mortality. The $\mathrm{ROC}_{\mathrm{AUC}}$ of each scale was compared with those with higher $\mathrm{ROC}_{\mathrm{AUC}}$ values, using the method described by DeLong et al [27]. The interobserver variability of the eight scales was assessed. A weighted Cohen kappa coefficient $(K)$ was calculated for each pair per scale used with $\mathrm{K}<0.2, \mathrm{~K}=0.21$ to $0.4, \mathrm{~K}=0.41$ to $0.6, \mathrm{~K}=0.61$ to 0.8 , and $\mathrm{k}>0.8$ corresponding to poor, fair, moderate, strong, and near- complete agreement, respectively [28]. We performed adjusted analyses 
via ordinal logistic or linear regression modelling, as appropriate. All statistics were carried out using JMP (version 14.0, SAS, Cary, NC, USA) except for the ROC analyses and kappa coefficient calculation, which were performed using MedCalc (version 9.2, MedCalc Software, Ostend, Belgium). Statistical significance was assumed at $p$ values of 0.05 and below.

\section{Results}

\section{Patient demographics}

During the study period, of 371 consecutive patients with SAH, 270 suffered acute aSAH and 230 met all inclusion criteria (Fig. 2). Of these, 200 patients survived for more than 7 days and were included in the analysis for factors related to $\mathrm{DCl}$. Patient characteristics are presented in Table 1 . A total of $47 \%$ of patients were classified as grade $3-5$ on the WFNS scale. The in-hospital mortality rate was $24 \%$. DCI was documented in 78 patients (39\%) and was related to poor outcome: $42 \%$ of patients presenting with DCl suffered a poor outcome (GOSE $1-4)$, whereas $26 \%$ of patients without DCI did so $(p<0.001)$. Poor neurological condition (WFNS 3-5) at admission to NCCU was statistically associated with poor neurological outcome $(p<0.001)$ and occurrence of $D C l(p=0.01)$. 
Table 1

Baseline Characteristics of Patients with Aneurysmal Subarachnoid Haemorrhage that Developed Poor or Good Outcome and that Developed or Did Not Delayed Cerebral Infarction (DCI).

\begin{tabular}{|c|c|c|c|c|c|c|c|}
\hline \multirow{2}{*}{ Variable } & \multirow[b]{2}{*}{$\begin{array}{l}\text { All } \\
\text { patients } \\
(n= \\
230)\end{array}$} & \multirow{2}{*}{$\begin{array}{l}\text { Outcome } \\
\text { Good } \\
\text { (GOSE } \\
5-8) \\
(n=135)\end{array}$} & \multirow{2}{*}{$\begin{array}{l}(n=230) \\
\text { Poor } \\
(G O S E \\
1-4) \\
(n=95)\end{array}$} & \multicolumn{3}{|c|}{$\mathrm{DCl}(\mathrm{n}=200)$} & \multirow[b]{2}{*}{$\begin{array}{l}P \\
\text { value } \\
\S\end{array}$} \\
\hline & & & & $\begin{array}{l}P \\
\text { value } \\
+\end{array}$ & $\begin{array}{l}\text { No } \\
(n= \\
122)\end{array}$ & $\begin{array}{l}\text { Yes } \\
(n= \\
78)\end{array}$ & \\
\hline \multicolumn{8}{|l|}{$\begin{array}{l}\text { Demographic } \\
\text { characteristics }\end{array}$} \\
\hline $\begin{array}{l}\text { Male sex - no. } \\
(\%)\end{array}$ & $96(42)$ & $49(36)$ & 47 (49) & 0.06 & 47 (39) & $\begin{array}{l}33 \\
(42)\end{array}$ & 0.66 \\
\hline Age $-y$ & $54 \pm 13$ & $52 \pm 12$ & $56 \pm 13$ & 0.01 & $54 \pm 13$ & $\begin{array}{l}52 \pm \\
12\end{array}$ & 0.20 \\
\hline \multicolumn{8}{|l|}{$\begin{array}{l}\text { Clinical } \\
\text { presentation }\end{array}$} \\
\hline GCS & $\begin{array}{l}13[7- \\
15]\end{array}$ & $\begin{array}{l}14[13- \\
15]\end{array}$ & $\begin{array}{l}8[5- \\
12]\end{array}$ & $\begin{array}{l}< \\
0.001\end{array}$ & $\begin{array}{l}14[10- \\
15]\end{array}$ & $\begin{array}{l}13[7- \\
14]\end{array}$ & 0.01 \\
\hline SAPS II & $\begin{array}{l}34[21- \\
49]\end{array}$ & $\begin{array}{l}25[18- \\
34]\end{array}$ & $\begin{array}{l}47 \\
{[39-} \\
54]\end{array}$ & $<.001$ & $\begin{array}{l}28[20- \\
41]\end{array}$ & $\begin{array}{l}33 \\
{[20-} \\
47]\end{array}$ & 0.15 \\
\hline WFNS scale & $3[1-4]$ & $2[1-4]$ & $4[3-5]$ & $<0.001$ & $2[1-4]$ & $\begin{array}{l}3[2- \\
4]\end{array}$ & 0.01 \\
\hline $3-5-$ no. $(\%)$ & $107(47)$ & $37(27)$ & $70(74)$ & $<.001$ & $51(42)$ & $\begin{array}{l}45 \\
(58)\end{array}$ & 0.03 \\
\hline \multicolumn{8}{|c|}{$\begin{array}{l}\text { Ruptured } \\
\text { aneurysm location } \\
- \text { no. }(\%)\end{array}$} \\
\hline $\begin{array}{l}\text { Anterior } \\
\text { circulation }\end{array}$ & $186(81)$ & 106 (79) & $80(84)$ & 0.31 & $\begin{array}{l}100 \\
(82)\end{array}$ & $\begin{array}{l}63 \\
(81)\end{array}$ & 0.85 \\
\hline ICA & $38(17)$ & $27(20)$ & $11(12)$ & 0.11 & $20(16)$ & $\begin{array}{l}12 \\
(15)\end{array}$ & 1.00 \\
\hline ACA & $20(9)$ & $16(12)$ & $4(4)$ & 0.06 & $14(11)$ & $5(6)$ & 0.32 \\
\hline MCA & $48(21)$ & $20(15)$ & $28(29)$ & 0.01 & $29(24)$ & $\begin{array}{l}15 \\
(19)\end{array}$ & 0.49 \\
\hline AcomA & $80(35)$ & $43(32)$ & 37 (39) & 0.33 & $37(30)$ & $\begin{array}{l}31 \\
(40)\end{array}$ & 0.22 \\
\hline $\begin{array}{l}\text { Posterior } \\
\text { circulation }\end{array}$ & $44(19)$ & $29(21)$ & $15(16)$ & 0.31 & $22(18)$ & $\begin{array}{l}15 \\
(19)\end{array}$ & 0.85 \\
\hline
\end{tabular}




\begin{tabular}{|c|c|c|c|c|c|c|c|}
\hline & & Outcome & $(n=230)$ & & $\mathrm{DCl}(n=200$ & & \\
\hline AcomP & $17(7)$ & $14(10)$ & $3(3)$ & 0.04 & $10(8)$ & $7(9)$ & 1.00 \\
\hline ACP & $3(1)$ & $1(1)$ & $2(2)$ & 0.57 & $1(1)$ & $2(3)$ & 0.56 \\
\hline PICA/AICA/SCA & $5(2)$ & $3(2)$ & $2(2)$ & 1.00 & $3(3)$ & $1(1)$ & 1.00 \\
\hline BA & $16(7)$ & $10(7)$ & $6(6)$ & 0.80 & $6(5)$ & $5(6)$ & 0.75 \\
\hline VA & $3(1)$ & $1(1)$ & $2(2)$ & 0.57 & $2(2)$ & $0(0)$ & 0.52 \\
\hline \multicolumn{8}{|l|}{$\begin{array}{l}\text { Aneurysm } \\
\text { treatment - no. } \\
(\%)\end{array}$} \\
\hline Coiling / Clipping & $\begin{array}{l}164(71) \\
/ 66 \\
(29)\end{array}$ & $\begin{array}{l}114(84) \\
/ 21(16)\end{array}$ & $\begin{array}{l}50(53) \\
/ 45 \\
(47)\end{array}$ & $\begin{array}{l}< \\
0.001\end{array}$ & $\begin{array}{l}91(75) \\
/ 31 \\
(25)\end{array}$ & $\begin{array}{l}64 \\
(82) / \\
14 \\
(18)\end{array}$ & 0.23 \\
\hline \multicolumn{8}{|l|}{$\begin{array}{l}\text { Complications - } \\
\text { no. }(\%)\end{array}$} \\
\hline $\begin{array}{l}\text { Early } \\
\text { hydrocephalus } \\
\text { requiring EVD }\end{array}$ & $121(53)$ & $60(44)$ & $61(64)$ & 0.003 & $57(47)$ & $\begin{array}{l}48 \\
(62)\end{array}$ & 0.38 \\
\hline $\begin{array}{l}\text { Intracerebral } \\
\text { hematoma }\end{array}$ & $69(30)$ & $24(18)$ & $45(47)$ & $\begin{array}{l}<.001 \\
0.01\end{array}$ & $36(30)$ & $\begin{array}{l}20 \\
(26)\end{array}$ & 0.63 \\
\hline Rebleeding & $21(9)$ & $5(4)$ & $16(17)$ & $\begin{array}{l}< \\
0.001\end{array}$ & $11(9)$ & $6(8)$ & 0.52 \\
\hline $\begin{array}{l}\text { Neurogenic } \\
\text { pulmonary edema }\end{array}$ & $10(4)$ & $7(5)$ & $3(3)$ & 0.53 & $2(2)$ & $8(10)$ & 0.01 \\
\hline $\begin{array}{l}\text { Angiographic } \\
\text { vasospasm }\end{array}$ & $81(35)$ & $48(36)$ & $33(35)$ & 1.00 & $5(4)$ & $\begin{array}{l}78 \\
(99)\end{array}$ & $<.001$ \\
\hline Minor & $30(13)$ & $19(14)$ & $11(12)$ & 0.69 & $5(4)$ & $\begin{array}{l}23 \\
(29)\end{array}$ & $<0.001$ \\
\hline Moderate & $28(34)$ & $19(39)$ & $9(26)$ & 0.31 & $0(0)$ & $\begin{array}{l}28 \\
(36)\end{array}$ & $<$. \\
\hline Severe & $26(31)$ & $11(22)$ & $15(44)$ & 0.09 & $0(0)$ & $\begin{array}{l}26 \\
(33)\end{array}$ & $<001$ \\
\hline $\begin{array}{l}\text { Cerebral salt- } \\
\text { wasting syndrome }\end{array}$ & $12(5)$ & $6(4)$ & $6(6)$ & 0.56 & $6(5)$ & $6(8)$ & 0.41 \\
\hline Seizure & $14(6)$ & $9(7)$ & $5(5)$ & 0.78 & $8(7)$ & $5(6)$ & 1.00 \\
\hline
\end{tabular}




\begin{tabular}{|c|c|c|c|c|c|c|c|}
\hline & & Outcome & $(n=230)$ & & $\mathrm{Ll}(\mathrm{n}=200$ & & \\
\hline $\begin{array}{l}\text { GOSE at } 3 \text { months } \\
\text { after SAH }\end{array}$ & $7[2-8]$ & $8[7-8]$ & $1[1-3]$ & $<.001$ & $8[4-8]$ & $\begin{array}{l}6[3- \\
8]\end{array}$ & 0.02 \\
\hline $\begin{array}{l}\text { In-hospital } \\
\text { mortality - no. } \\
(\%)\end{array}$ & $55(24)$ & $0(0)$ & $55(58)$ & $<.001$ & $16(13)$ & $9(12)$ & 0.83 \\
\hline \multicolumn{8}{|c|}{ Results are noted as numbers (\%), medians [interquartile range], or means \pm SD. } \\
\hline \multicolumn{8}{|c|}{$\begin{array}{l}\text { * Data for DCl were collected from a group of } 200 \text { patients ( } 30 \text { patients who died before day } 7 \text { were } \\
\text { excluded). }\end{array}$} \\
\hline \multicolumn{8}{|c|}{ † P value for patients with good outcome versus poor outcome. } \\
\hline \multicolumn{8}{|c|}{$\S \mathrm{P}$ value for patients with $\mathrm{DCl}$ versus without $\mathrm{DCl}$. } \\
\hline \multicolumn{8}{|c|}{ Boldface values represent significant findings assumed at $p$ values of 0.05 and below. } \\
\hline \multicolumn{8}{|c|}{$\begin{array}{l}\text { ACA denotes anterior cerebral artery; ACP, posterior cerebral artery; AICA, anterior inferior cerebellar } \\
\text { artery; AcomA, anterior communicating artery; AcomP, posterior communicating artery; BA, basilar } \\
\text { artery; EVD, external ventricular drain; GCS, Glasgow Coma Scale; GOSE, Glasgow Outcome Scale } \\
\text { Extended; ICA, internal carotid artery; MCA, middle cerebral artery; SAPS II, Simplified Acute } \\
\text { Physiologic Score II; SCA, superior cerebellar artery; PICA, posterior inferior cerebellar artery; VA, } \\
\text { vertebral artery; and WFNS, World Federation of Neurological Surgeons Grading System. }\end{array}$} \\
\hline
\end{tabular}

\section{Predictive value of CT grading systems}

For all tested scales or scores, a higher value was statistically associated with occurrence of $\mathrm{DCl}$ and poor neurological outcome (Table 2). Figure 3A summarizes the results of ROC curves of the main predictors of $\mathrm{DCl}$. Additional file 1 (Table S2) shows the cut-off values with corresponding specificity and sensitivity and $\mathrm{ROC}_{\mathrm{AUC}}$ for each predictor. The Hijdra scale performed best at predicting $\mathrm{DCl}$, with a $\mathrm{ROC}_{\mathrm{AUC}}$ of 0.80 (95\% confidence interval [Cl], 0.74-0.85). The ideal cut-off was a Hijdra scale score $\geq 20$, with a sensitivity of $85 \%(95 \% \mathrm{Cl}, 75-92 \%$ and a specificity of $63 \%(95 \% \mathrm{Cl}, 54-71 \%)$, but it was less accurate to predict poor outcome (Fig. 3B) or death (Fig. 3C) than the SAPS II score (ROC AUC respectively $0.86[95 \% \mathrm{Cl}, 0.71-0.91]$ and $0.82[95 \% \mathrm{Cl}, 0.76-0.86])$. Figure 4 shows the occurrence of $\mathrm{DCl}$ in the subpopulation of low-severity aSAH (WFNS 1-2) and high-severity aSAH (WFNS 3-5). In the WFNS 1-2 subpopulation, the Hijdra scale was also the best-performing scale to predict $\mathrm{DCl}$, with a $\mathrm{ROC}_{\mathrm{AUC}}$ of 0.82 (95\% Cl, 0.73-0.89) (Additional file 1 - Fig. S1). The IVH score performed best for predicting early hydrocephalus requiring EVD, with a $\mathrm{ROC}_{\mathrm{AUC}}$ of 0.85 (95\% $\left.\mathrm{Cl}, 0.79-0.89\right)$ (Fig. 3D). On univariate analysis, the Hijdra scale and IVH score were of significant prognostic value for the presence of $\mathrm{DCl}$ and of early hydrocephalus requiring EVD (Additional file 1 - Table S3). The Fisher scale did not predict any of the three outcome measures. 
Table 2

Relationship between CT Grading Systems and the Development of Poor Outcome or Delayed Cerebral Infarction (DCl) in Patients with Aneurysmal Subarachnoid Haemorrhage.

\begin{tabular}{|c|c|c|c|c|c|c|c|}
\hline & & Outcome & & 30) & $(n=200)$ & & \\
\hline $\begin{array}{l}\text { CT Grading } \\
\text { Systems }\end{array}$ & $\begin{array}{l}\text { All } \\
\text { patients } \\
(\mathrm{N}= \\
230)\end{array}$ & $\begin{array}{l}\text { Good } \\
\text { (GOSE } \\
5-8) \\
(n= \\
135)\end{array}$ & $\begin{array}{l}\text { Poor } \\
\text { (GOSE } \\
1-4) \\
(n=95)\end{array}$ & $\begin{array}{l}P \\
\text { value } \\
t\end{array}$ & $\begin{array}{l}\text { No } \\
(\mathrm{n}= \\
122)\end{array}$ & $\begin{array}{l}\text { Yes } \\
(n=78)\end{array}$ & $\begin{array}{l}\mathrm{P} \\
\text { value } \\
\S\end{array}$ \\
\hline Fisher grade & $4[4-4]$ & $4[3-5]$ & $4[4-4]$ & 0.05 & $4[3-4]$ & $4[4-4]$ & 0.04 \\
\hline $3-4-$ no. $(\%)$ & $210(91)$ & $115(83)$ & $95(100)$ & $\begin{array}{l}<.001 \\
0.00\end{array}$ & $\begin{array}{l}103 \\
(84)\end{array}$ & 77 (99) & $\begin{array}{l}< \\
0.001\end{array}$ \\
\hline $\begin{array}{l}\text { modified } \\
\text { Fisher grade }\end{array}$ & $4[3-4]$ & $4[2-4]$ & $4[4-4]$ & $\dot{0.001}$ & $4[2-4]$ & $4[4-4]$ & $\dot{0} .001$ \\
\hline III-IV - no. (\%) & $194(85)$ & $99(74)$ & $95(100)$ & $\dot{0} 001$ & $88(73)$ & $76(97)$ & $\begin{array}{l}<.001 \\
0.00\end{array}$ \\
\hline Claassen scale & $3[3-4]$ & $3[2-4]$ & $4[3-4]$ & $<.001$ & $3[2-4]$ & $4[3-4]$ & $\hat{0}_{0.001}$ \\
\hline III-IV - no. (\%) & $193(84)$ & $99(74)$ & $94(99)$ & $\dot{0}_{0.001}$ & $88(73)$ & $76(97)$ & $<$. \\
\hline $\begin{array}{l}\text { BNI grading } \\
\text { scale }\end{array}$ & $4[3-5]$ & $4[3-5]$ & $5[4-5]$ & $\begin{array}{l}< \\
0.001\end{array}$ & $4[3-5]$ & $4[4-5]$ & 0.003 \\
\hline IV-V - no. (\%) & $167(73)$ & $81(60)$ & $86(91)$ & $<0.001$ & $73(60)$ & $67(86)$ & $\begin{array}{l}< \\
0.001\end{array}$ \\
\hline IVH score & $7[0-11]$ & $5[0-10]$ & $\begin{array}{l}10[4- \\
17]\end{array}$ & $\dot{0}_{0.001}$ & $\begin{array}{l}5[0- \\
10]\end{array}$ & $\begin{array}{l}8[2- \\
11]\end{array}$ & 0.006 \\
\hline
\end{tabular}
* Data for $\mathrm{DCl}$ were collected from a group of 200 patients (30 patients who died before day 7 were excluded).

Results are expressed as numbers (\%), medians [interquartile range], or means \pm SD.

† $\mathrm{P}$ value for patients with good outcome versus poor outcome.

$\S \mathrm{P}$ value for patients with $\mathrm{DCl}$ versus without $\mathrm{DCl}$.

Boldface values represent significant findings assumed at $p$ values of 0.05 and below.

BNI denotes Barrow Neurological Institute score; CT, computerized tomography; GOSE, Extended Glasgow Outcome Scale; and IVH, Intraventricular Haemorrhage. 


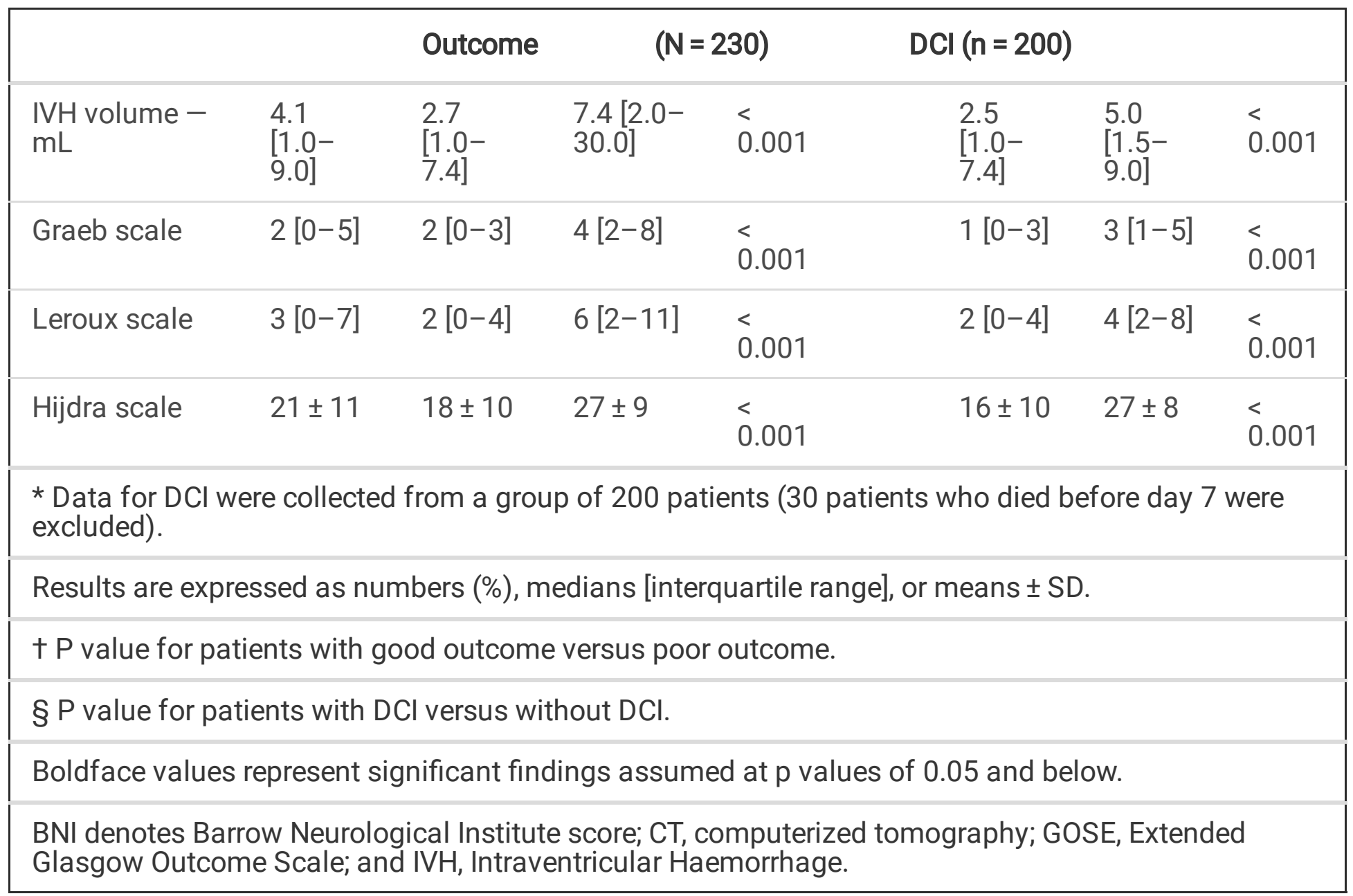

\section{Rating interobserver agreement}

All scales were rated as having a good or very good interobserver agreement. The rating scale with the greatest interobserver agreement was the Fisher scale $(\mathrm{K}=0.91 ; 95 \% \mathrm{Cl}, 0.75-1.00)$, followed by the Hijdra score $(\mathrm{k}=0.85 ; 95 \% \mathrm{Cl}, 0.80-0.91)$ (Additional file 1 - Table S4). The lowest interobserver agreement was observed with the IVH score $(\mathrm{K}=0.69 ; 95 \% \mathrm{Cl}, 0.56-0.83)$.

\section{Multivariate analysis of CT grading systems and clinical parameters}

A multivariate analysis was performed including the significant factors 'clinical grade' and 'age' from the univariate analysis (Table 3). Only SAPS II (adjusted odds ratio per unit, 1.06; 95\% Cl, 1.03-1.10; $\mathrm{p}<$ 0.001 ) and rebleeding (odds ratio, 9.29; $95 \% \mathrm{Cl}, 2.19-52.60 ; \mathrm{p}=0.01$ ) were associated with poor outcome. The Hijdra scale was the only variable with significant prognostic value for the presence of $\mathrm{DCl}$ (adjusted odds ratio per unit, $1.18 ; 95 \% \mathrm{Cl}, 1.10-1.27 ; \mathrm{p}<0.001)$. IVH score was the most significant predictor for the occurrence of early hydrocephalus (odds ratio, 1.49; $95 \% \mathrm{Cl}, 1.22-1.85 ; \mathrm{p}<0.001$ ). Of interest, SAPS II was significantly associated with early hydrocephalus occurrence (adjusted odds ratio per unit, 1.04; 95\% $\mathrm{Cl}, 1.00-1.07 ; \mathrm{p}=0.04$ ), whereas a clipping procedure was protective against early hydrocephalus (odds ratio, $0.27 ; 95 \% \mathrm{Cl}, 0.090 .76 ; p=0.02)$. 
Table 3

Multivariate Statistical analysis of Significant Risk Factors for Poor Patient Outcome (GOSE 1-4), Delayed Cerebral Infarction (DCl) and Early Hydrocephalus Requiring EVD.

\begin{tabular}{|c|c|c|c|c|c|c|c|}
\hline & & $\begin{array}{l}\text { Poor } \\
\text { outcome }\end{array}$ & & DClt & & $\begin{array}{l}\text { Early } \\
\text { hydrocephal }\end{array}$ & \\
\hline & $\begin{array}{l}\text { Numerical } \\
\text { values* }\end{array}$ & $\begin{array}{l}\text { Odds ratio } \\
{[95 \% \mathrm{Cl}]}\end{array}$ & $\begin{array}{l}\mathrm{P} \\
\text { value }\end{array}$ & $\begin{array}{l}\text { Odds ratio } \\
{[95 \% \mathrm{Cl}]}\end{array}$ & $\begin{array}{l}\mathrm{P} \\
\text { value }\end{array}$ & $\begin{array}{l}\text { Odds ratio } \\
{[95 \% \text { Cl] }}\end{array}$ & $\begin{array}{l}\mathrm{P} \\
\text { value }\end{array}$ \\
\hline SAPS II & $0-163$ & $\begin{array}{l}1.06[1.03- \\
1.10]\end{array}$ & $<.001$ & $\begin{array}{l}0.99 \\
{[0.96-} \\
1.02]\end{array}$ & 0.61 & $\begin{array}{l}1.04[1.00- \\
1.07]\end{array}$ & 0.04 \\
\hline Clipping & 0,1 & $\begin{array}{l}2.09[0.82 \\
-5.43]\end{array}$ & 0.12 & $\begin{array}{l}0.72 \\
{[0.25-} \\
2.02]\end{array}$ & 0.53 & $\begin{array}{l}0.27[0.09- \\
0.76]\end{array}$ & 0.02 \\
\hline Rebleeding & 0,1 & $\begin{array}{l}9.29[2.19 \\
-52.6]\end{array}$ & 0.01 & $\begin{array}{l}0.94 \\
{[0.22-} \\
3.80]\end{array}$ & 0.93 & $\begin{array}{l}3.83[0.92- \\
19.1]\end{array}$ & 0.08 \\
\hline $\begin{array}{l}\text { Hijdra } \\
\text { scale }\end{array}$ & $0-42$ & $\begin{array}{l}1.03[0.97- \\
1.10]\end{array}$ & 0.38 & $\begin{array}{l}1.18 \\
{[1.10-} \\
1.27]\end{array}$ & $\begin{array}{l}<.001 \\
0\end{array}$ & $\begin{array}{l}1.02[0.96- \\
1.09]^{-}\end{array}$ & 0.47 \\
\hline IVH score & $0-23$ & $\begin{array}{l}0.91[0.75- \\
1.10]\end{array}$ & 0.32 & $\begin{array}{l}0.84 \\
{[0.70-} \\
1.00]\end{array}$ & 0.06 & $\begin{array}{l}1.49[1.22- \\
1.85]^{[}\end{array}$ & $\begin{array}{l}<.001 \\
\end{array}$ \\
\hline \multicolumn{8}{|c|}{ * $0=$ no, $1=$ yes. } \\
\hline \multicolumn{8}{|c|}{$\begin{array}{l}\text { TData for DCI were collected from a group of } 200 \text { patients ( } 30 \text { patients who died before day } 7 \text { were } \\
\text { excluded). }\end{array}$} \\
\hline \multicolumn{8}{|c|}{ Boldface values represent significant findings assumed at $p$ values of 0.05 and below. } \\
\hline \multicolumn{8}{|c|}{$\begin{array}{l}\text { The odds ratio is to be interpreted as follows: for example, for each point increase in SAPS II, the risk } \\
\text { for poor outcome increases by } 6 \%(95 \% \mathrm{Cl}, 3-10 \%) \text {. }\end{array}$} \\
\hline
\end{tabular}

\section{Discussion}

Many studies have compared clinical grading scales such as the Hunt and Hess scale, WFNS, and Glasgow Coma Scale for predicting unfavourable outcome in aSAH [29,30]. To our knowledge, however, this study is the first to compare eight radiological scales, grading subarachnoid or ventricular haemorrhage or both for the prediction of $\mathrm{DCl}$, acute hydrocephalus, and functional outcome at 3 months in a large aSAH population. We identified a $39 \%$ rate of $\mathrm{DCl}$ in our aSAH population, in agreement with studies using a modern definition of $\mathrm{DCl}$ [31]. As previously reported, the Fisher scale failed to predict vasospasm or DCl occurrence, with both poor sensitivity and poor specificity $[6,7,9,10]$. We confirmed 
that the Fisher scale could not predict any of the three outcome measures. We note that in our ICU population, $91 \%$ of all patients were classified Fisher grade $3-4$, which may have confounded statistical analysis.

The Hijdra scale was the most effective scale for predicting DCl, with an ideal cut-off of 20/42 and excellent interobserver agreement. This scale has been studied mostly for its association with functional outcome and has been found to be superior to the Fisher scale [12,32]. Dupont et al [33] also reported that a Hijdra score $\geq 23$ was strongly associated with the occurrence of vasospasm, and our findings show a strong association of Hijdra score with $\mathrm{DCl}$. The design of the grading system may explain these results. Because DCl development and outcome correlate with the amount of blood on CT scan $[4,5,7,9$, $33,34]$, grading every cistern and every ventricle likely assesses the overall bleeding with greater precision than other scales. Despite its apparent complexity, the Hijdra scale had a good reliability, and we found an excellent interobserver agreement for it $[12,35,36]$. Of interest, both sensitivity and specificity were increased in a WFNS 1-2 subpopulation. In fact, with an ideal cut-off of $18 / 42$, the Hijdra scale had $88 \%$ sensitivity and $69 \%$ specificity for DCl prognosis (only $4 / 54$ patients had DCl with a Hijdra scale score < 18/42). Associated with clinically predictive factors such as smoking, history of diabetes, and hypertension [31], the Hijdra scale could help physicians to better predict $\mathrm{DCl}$ occurrence and determine the most appropriate hospitalization unit for these aSAH patients.

Acute hydrocephalus is a frequent complication after brain aneurysm rupture [37-39]. In our ICU population, 53\% patients needed an EVD. We found that the IVH score best predicted acute hydrocephalus requiring EVD. Moreover, this score stood out from the Graeb and Leroux scores by allowing for reliable estimation of intraventricular bleeding volume [17]. In a 2012 study, Hwang et al found that the IVH score could reliably predict poor neurological outcome, which was associated with an estimated IVH volume $>6 \mathrm{~mL}$ [40]. Recently, the interval to blood clearance in the basal cisterns and peripheral subarachnoid spaces has been associated with shunt dependency. In this study, patients with a shorter interval of blood clearance required a shorter duration of shunt use than other patients [41]. Thus, accurate evaluation of blood volume on CT scans using quantitative scales or automated computer blood quantification could be useful for aSAH management [42].

SAPS II was the best predictor of poor outcome at 3 and 6 months in our study. This score was generated from a cohort of medical and surgical ICU patients and was not intended to assess mortality in neurological patients. This expected finding illustrates the importance of clinical variables included in the SAPS II scale, particularly age and initial Glasgow Coma Scale score [23]. Indeed, the initial neurological assessment by means of the Glasgow Coma Scale or WFNS scale is a crucial determinant for neurological outcome and death $[22,29,43,44]$. New grading scales using both clinical and radiological scores (SAFIR grading scale [45], Southwestern Severity Index [46]) have shown promising results but always use Fisher scale, which is not sufficiently reliable. Future composite scores should include the Hijdra scale to improve accuracy. Because of its complex and time-consuming nature, an automated approach to the Hijdra scale could be developed to facilitate clinical use [42]. 
The main limitation of this study arises from its retrospective nature with accordingly lower accuracy and lower completeness of the recorded data, compared to a prospectively collected cohort. Consequently, some degree of bias is inevitable. To avoid some of this inherent bias, the two observers analysing the CT scans were blinded to clinical outcome and $\mathrm{DCl}$ occurrence. Our cohort included neurological ICU patients. Consequently, the less severely ill patients, who probably had the lowest amounts of blood and lowest risk for $\mathrm{DCl}$, were likely not included. Finally, the exclusion of patients with non-aneurysmal haemorrhage (peri-mesencephalic, traumatic, or arteriovenous malformation) biased the data toward a relatively high overall risk of $\mathrm{DCl}$ and poor outcome. Nevertheless, $\mathrm{DCl}$ occurred in $39 \%$ of patients, which is comparable to proportions in other recent studies [31].

\section{Conclusion}

Radiological grading of SAH is useful for predicting DCl risk. Among these scales, the Hijdra scale seems to be the most effective at predicting the occurrence of $\mathrm{DCl}$. An automated computer quantification approach for this scale could facilitate its daily use. This evaluation associated with clinical predictive values could help physicians better use critical care resources for these patients.

\section{Declarations}

\section{Ethical approval and consent to participate}

The study was performed in accordance with the Declaration of Helsinki and approved by the Ethics Committee (Comité d'éthique pour la recherche en Anesthésie-Réanimation - IRB 000102542019081), which waived the requirement for individual consent according to French law at the time of the study.

\section{Consent for publication}

Not applicable. No consent for publication was requested for this study in accordance to French law at the time of the study

\section{Availability of supporting data}

The anonymized datasets analysed during the current study are available from the corresponding author on reasonable request.

\section{Competing interests}

The authors have no personal financial or institutional interest in any of the drugs, materials, or devices described in this article.

\section{Funding}

No external funding has been obtained for this reasearch. 


\section{Authors' contributions}

Along with the first author (DC), PS and LV made substantial contributions to the conception and design, acquisition of data, and analysis and interpretation of data; TG, HD, OM, and NB were involved in drafting the manuscript and revising it critically for important intellectual content; SM and SB participated in designing and performing the statistical analyses; $A A, D C$, and $L G$ were involved in data collection and preparation of the report. AR, HB, and ND assisted in the evaluation of the radiographic data. All authors read and approved the final manuscript.

\section{Acknowledgements}

We would like to thank to our ICU and neuroradiologist colleagues for supporting our study.

\section{Authors' information}

David Couret, Department of Anaesthesiology and Critical Care Medicine, Aix Marseille Univ, University Hospital Timone, Marseille, France; Neurocritical Care Unit, University Hospital Saint Pierre, Réunion Univ, BP 350, Saint Pierre 97448 La Réunion, France; Reunion Island University, INSERM, Diabète Athérothrombose Réunion Océan Indien (DéTROI), Saint Denis de la Réunion, France. david.couret@chureunion.fr

Salah Boussen, Department of Anaesthesiology and Critical Care Medicine, Aix Marseille Univ, University Hospital Timone, Marseille, France. michelsalah.boussen@ap-hm.fr

Dan Cardoso, Department of Anaesthesiology and Critical Care Medicine, Aix Marseille Univ, University Hospital Timone, Marseille, France. dan.cardoso@hotmail.fr

Audrey Alonzo, Department of Anaesthesiology and Critical Care Medicine, Aix Marseille Univ, University Hospital Timone, Marseille, France.nanou-aud@hotmail.fr

Sylvain Madec, Department of Anaesthesiology and Critical Care Medicine, Aix Marseille Univ, University Hospital Timone, Marseille, France. symadec@gmail.com

Anthony Reyre, Department of radiology, University Hospital Timone, Aix Marseille University, Marseille, France. anthony.reyre@ap-hm.fr

Hervé Brunel, Department of radiology, University Hospital Timone, Aix Marseille University, Marseille, France. herve.brunel@ap-hm.fr

Nadine Girard, Department of radiology, University Hospital Timone, Aix Marseille University, Marseille, France.nadine.girard@ap-hm.fr

Thomas Graillon, Department of Neurosurgery, University Hospital Timone, Aix Marseille University, Marseille, France. thomas.graillon@ap-hm.fr 
Henry Dufour, Department of Neurosurgery, University Hospital Timone, Aix Marseille University, Marseille, France. henry.dufour@ap-hm.fr

Nicolas Bruder, Department of Anaesthesiology and Critical Care Medicine, Aix Marseille Univ, University Hospital Timone, Marseille, France. nicolas.bruder@ap-hm.fr

Pierre Simeone, Department of Anaesthesiology and Critical Care Medicine, Aix Marseille Univ, University Hospital Timone, Marseille, France; CNRS, INT, Inst Neurosci Timone, Aix Marseille Univ, Marseille, France. pierre.simeone@ap-hm.fr

Olivier Meilhac, Reunion Island University, INSERM, Diabète Athérothrombose Réunion Océan Indien (DéTROI), Saint Denis de la Réunion, France. olivier.meilhac@inserm.fr

Lionel Velly, Department of Anaesthesiology and Critical Care Medicine, Aix Marseille Univ, University Hospital Timone, Marseille, France ; CNRS, INT, Inst Neurosci Timone, Aix Marseille Univ, Marseille, France. : lionel.velly@ap-hm.fr

\section{References}

1. Velly LJ, Bilotta F, Fabregas N, Soehle M, Bruder NJ, Nathanson MH, European N, Critical Care Interest $\mathrm{G}$ : Anaesthetic and ICU management of aneurysmal subarachnoid haemorrhage: a survey of European practice. Eur J Anaesthesiol 2015, 32(3):168-176.

2. Triglia T, Mezzapesa A, Martin JC, Verdier M, Lagier D, Dufour H, Bruder N, Alessi MC, Velly LJ: Early matrix metalloproteinase- 9 concentration in the first $48 \mathrm{~h}$ after aneurysmal subarachnoid haemorrhage predicts delayed cerebral ischaemia: An observational study. Eur J Anaesthesio/ 2016, 33(9):662-669.

3. Berman MF, Solomon RA, Mayer SA, Johnston SC, Yung PP: Impact of hospital-related factors on outcome after treatment of cerebral aneurysms. Stroke 2003, 34(9):2200-2207.

4. Fisher CM, Kistler JP, Davis JM: Relation of cerebral vasospasm to subarachnoid hemorrhage visualized by computerized tomographic scanning. Neurosurgery 1980, 6(1):1-9.

5. Hijdra A, van Gijn J, Nagelkerke NJ, Vermeulen M, van Crevel H: Prediction of delayed cerebral ischemia, rebleeding, and outcome after aneurysmal subarachnoid hemorrhage. Stroke 1988, 19(10):1250-1256.

6. Kramer AH, Hehir M, Nathan B, Gress D, Dumont AS, Kassell NF, Bleck TP: A comparison of 3 radiographic scales for the prediction of delayed ischemia and prognosis following subarachnoid hemorrhage. J Neurosurg 2008, 109(2):199-207.

7. Claassen J, Bernardini GL, Kreiter K, Bates J, Du YE, Copeland D, Connolly ES, Mayer SA: Effect of cisternal and ventricular blood on risk of delayed cerebral ischemia after subarachnoid hemorrhage: the Fisher scale revisited. Stroke 2001, 32(9):2012-2020. 
8. Hijdra A, Brouwers PJ, Vermeulen M, van Gijn J: Grading the amount of blood on computed tomograms after subarachnoid hemorrhage. Stroke 1990, 21(8):1156-1161.

9. Frontera JA, Claassen J, Schmidt JM, Wartenberg KE, Temes R, Connolly ES, Jr., MacDonald RL, Mayer SA: Prediction of symptomatic vasospasm after subarachnoid hemorrhage: the modified fisher scale. Neurosurgery 2006, 59(1):21-27; discussion 21-27.

10. Wilson DA, Nakaji P, Abla AA, Uschold TD, Fusco DJ, Oppenlander ME, Albuquerque FC, McDougall CG, Zabramski JM, Spetzler RF: A simple and quantitative method to predict symptomatic vasospasm after subarachnoid hemorrhage based on computed tomography: beyond the Fisher scale. Neurosurgery 2012, 71(4):869-875.

11. Dengler NF, Diesing D, Sarrafzadeh A, Wolf S, Vajkoczy P: The Barrow Neurological Institute Scale Revisited: Predictive Capabilities for Cerebral Infarction and Clinical Outcome in Patients With Aneurysmal Subarachnoid Hemorrhage. Neurosurgery 2017, 81(2):341-349.

12. Jimenez-Roldan L, Alen JF, Gomez PA, Lobato RD, Ramos A, Munarriz PM, Lagares A: Volumetric analysis of subarachnoid hemorrhage: assessment of the reliability of two computerized methods and their comparison with other radiographic scales. J Neurosurg 2013, 118(1):84-93.

13. van der Steen WE, Leemans EL, van den Berg R, Roos Y, Marquering HA, Verbaan D, Majoie C: Radiological scales predicting delayed cerebral ischemia in subarachnoid hemorrhage: systematic review and meta-analysis. Neuroradiology 2019, 61(3):247-256.

14. Smith ML, Abrahams JM, Chandela S, Smith MJ, Hurst RW, Le Roux PD: Subarachnoid hemorrhage on computed tomography scanning and the development of cerebral vasospasm: the Fisher grade revisited. Surg Neurol 2005, 63(3):229-234; discussion 234-225.

15. Graeb DA, Robertson WD, Lapointe JS, Nugent RA, Harrison PB: Computed tomographic diagnosis of intraventricular hemorrhage. Etiology and prognosis. Radiology 1982, 143(1):91-96.

16. LeRoux PD, Haglund MM, Newell DW, Grady MS, Winn HR: Intraventricular hemorrhage in blunt head trauma: an analysis of 43 cases. Neurosurgery 1992, 31(4):678-684; discussion 684-675.

17. Hallevi H, Dar NS, Barreto AD, Morales MM, Martin-Schild S, Abraham AT, Walker KC, Gonzales NR, Illoh K, Grotta JC et al: The IVH score: a novel tool for estimating intraventricular hemorrhage volume: clinical and research implications. Crit Care Med 2009, 37(3):969-974, e961.

18. von Elm E, Altman DG, Egger M, Pocock SJ, Gotzsche PC, Vandenbroucke JP, Initiative S: The Strengthening the Reporting of Observational Studies in Epidemiology (STROBE) statement: guidelines for reporting observational studies. Lancet 2007, 370(9596):1453-1457.

19. Toulouse E, Masseguin C, Lafont B, McGurk G, Harbonn A, J AR, Granier S, Dupeyron A, Bazin JE: French legal approach to clinical research. Anaesth Crit Care Pain Med 2018, 37(6):607-614.

20. Steiner T, Juvela S, Unterberg A, Jung C, Forsting M, Rinkel G, European Stroke O: European Stroke Organization guidelines for the management of intracranial aneurysms and subarachnoid haemorrhage. Cerebrovasc Dis 2013, 35(2):93-112.

21. Teasdale G, Jennett B: Assessment of coma and impaired consciousness. A practical scale. Lancet 1974, 2(7872):81-84. 
22. Report of World Federation of Neurological Surgeons Committee on a Universal Subarachnoid Hemorrhage Grading Scale. J Neurosurg 1988, 68(6):985-986.

23. Le Gall JR, Lemeshow S, Saulnier F: A new Simplified Acute Physiology Score (SAPS II) based on a European/North American multicenter study. JAMA 1993, 270(24):2957-2963.

24. Diringer MN, Bleck TP, Claude Hemphill J, 3rd, Menon D, Shutter L, Vespa P, Bruder N, Connolly ES, Jr., Citerio G, Gress $D$ et al: Critical care management of patients following aneurysmal subarachnoid hemorrhage: recommendations from the Neurocritical Care Society's Multidisciplinary Consensus Conference. Neurocrit Care 2011, 15(2):211-240.

25. Vergouwen MD, Vermeulen M, van Gijn J, Rinkel GJ, Wijdicks EF, Muizelaar JP, Mendelow AD, Juvela $\mathrm{S}$, Yonas $\mathrm{H}$, Terbrugge KG et al: Definition of delayed cerebral ischemia after aneurysmal subarachnoid hemorrhage as an outcome event in clinical trials and observational studies: proposal of a multidisciplinary research group. Stroke 2010, 41(10):2391-2395.

26. Jennett B, Bond M: Assessment of outcome after severe brain damage. Lancet 1975, 1(7905):480484.

27. DeLong ER, DeLong DM, Clarke-Pearson DL: Comparing the areas under two or more correlated receiver operating characteristic curves: a nonparametric approach. Biometrics 1988, 44(3):837-845.

28. Landis JR, Koch GG: The measurement of observer agreement for categorical data. Biometrics 1977, 33(1):159-174.

29. Aggarwal A, Dhandapani S, Praneeth K, Sodhi HBS, Pal SS, Gaudihalli S, Khandelwal N, Mukherjee KK, Tewari MK, Gupta SK et al: Comparative evaluation of H\&H and WFNS grading scales with modified H\&H (sans systemic disease): A study on 1000 patients with subarachnoid hemorrhage. Neurosurg Rev 2018, 41(1):241-247.

30. St Julien J, Bandeen-Roche K, Tamargo RJ: Validation of an aneurysmal subarachnoid hemorrhage grading scale in 1532 consecutive patients. Neurosurgery 2008, 63(2):204-210; discussion 210-201.

31. de Rooij NK, Rinkel GJ, Dankbaar JW, Frijns CJ: Delayed cerebral ischemia after subarachnoid hemorrhage: a systematic review of clinical, laboratory, and radiological predictors. Stroke 2013, 44(1):43-54.

32. Bretz JS, Von Dincklage F, Woitzik J, Winkler MK, Major S, Dreier JP, Bohner G, Scheel M: The Hijdra scale has significant prognostic value for the functional outcome of Fisher grade 3 patients with subarachnoid hemorrhage. Clin Neuroradiol 2016.

33. Dupont SA, Wijdicks EF, Manno EM, Lanzino G, Rabinstein AA: Prediction of angiographic vasospasm after aneurysmal subarachnoid hemorrhage: value of the Hijdra sum scoring system. Neurocrit Care 2009, 11(2):172-176.

34. Nieuwkamp DJ, Setz LE, Algra A, Linn FH, de Rooij NK, Rinkel GJ: Changes in case fatality of aneurysmal subarachnoid haemorrhage over time, according to age, sex, and region: a metaanalysis. Lancet Neuro/ 2009, 8(7):635-642.

35. van Norden AG, van Dijk GW, van Huizen MD, Algra A, Rinkel GJ: Interobserver agreement and predictive value for outcome of two rating scales for the amount of extravasated blood after 
aneurysmal subarachnoid haemorrhage. J Neurol 2006, 253(9):1217-1220.

36. Ibrahim GM, Weidauer S, Macdonald RL: Interobserver variability in the interpretation of computed tomography following aneurysmal subarachnoid hemorrhage. J Neurosurg 2011, 115(6):1191-1196.

37. Sheehan JP, Polin RS, Sheehan JM, Baskaya MK, Kassell NF: Factors associated with hydrocephalus after aneurysmal subarachnoid hemorrhage. Neurosurgery 1999, 45(5):1120-1127; discussion 11271128.

38. Varelas P, Helms A, Sinson G, Spanaki M, Hacein-Bey L: Clipping or coiling of ruptured cerebral aneurysms and shunt-dependent hydrocephalus. Neurocrit Care 2006, 4(3):223-228.

39. Gruber A, Reinprecht A, Bavinzski G, Czech T, Richling B: Chronic shunt-dependent hydrocephalus after early surgical and early endovascular treatment of ruptured intracranial aneurysms. Neurosurgery 1999, 44(3):503-509; discussion 509-512.

40. Hwang BY, Bruce SS, Appelboom G, Piazza MA, Carpenter AM, Gigante PR, Kellner CP, Ducruet AF, Kellner MA, Deb-Sen R et al: Evaluation of intraventricular hemorrhage assessment methods for predicting outcome following intracerebral hemorrhage. J Neurosurg 2012, 116(1):185-192.

41. Mijderwijk HJ, Fischer I, Zhivotovskaya A, Bostelmann R, Steiger HJ, Cornelius JF, Petridis AK: Prognostic Model for Chronic Shunt-Dependent Hydrocephalus After Aneurysmal Subarachnoid Hemorrhage. World Neurosurg 2019.

42. Boers AM, Zijlstra IA, Gathier CS, van den Berg R, Slump CH, Marquering HA, Majoie CB: Automatic quantification of subarachnoid hemorrhage on noncontrast CT. AJNR Am J Neuroradio/ 2014, 35(12):2279-2286.

43. van Heuven AW, Dorhout Mees SM, Algra A, Rinkel GJ: Validation of a prognostic subarachnoid hemorrhage grading scale derived directly from the Glasgow Coma Scale. Stroke 2008, 39(4):13471348.

44. Aggarwal A, Dhandapani S, Praneeth K, Sodhi HB, Pal SS, Gaudihalli S, Khandelwal N, Mukherjee KK, Tewari MK, Gupta SK et al: Comparative evaluation of H\&H and WFNS grading scales with modified H\&H (sans systemic disease): A study on 1000 patients with subarachnoid hemorrhage. Neurosurg Rev 2017.

45. van Donkelaar CE, Bakker NA, Birks J, Veeger N, Metzemaekers JDM, Molyneux AJ, Groen RJM, van Dijk JMC: Prediction of Outcome After Aneurysmal Subarachnoid Hemorrhage. Stroke 2019, 50(4):837-844.

46. Ban VS, El Ahmadieh TY, Aoun SG, Plitt AR, Lyon KA, Eddleman C, Beecher J, McDougall CM, Reisch J, Welch BG et al: Prediction of Outcomes for Ruptured Aneurysm Surgery. Stroke 2019, 50(3):595601.

\section{Figures}




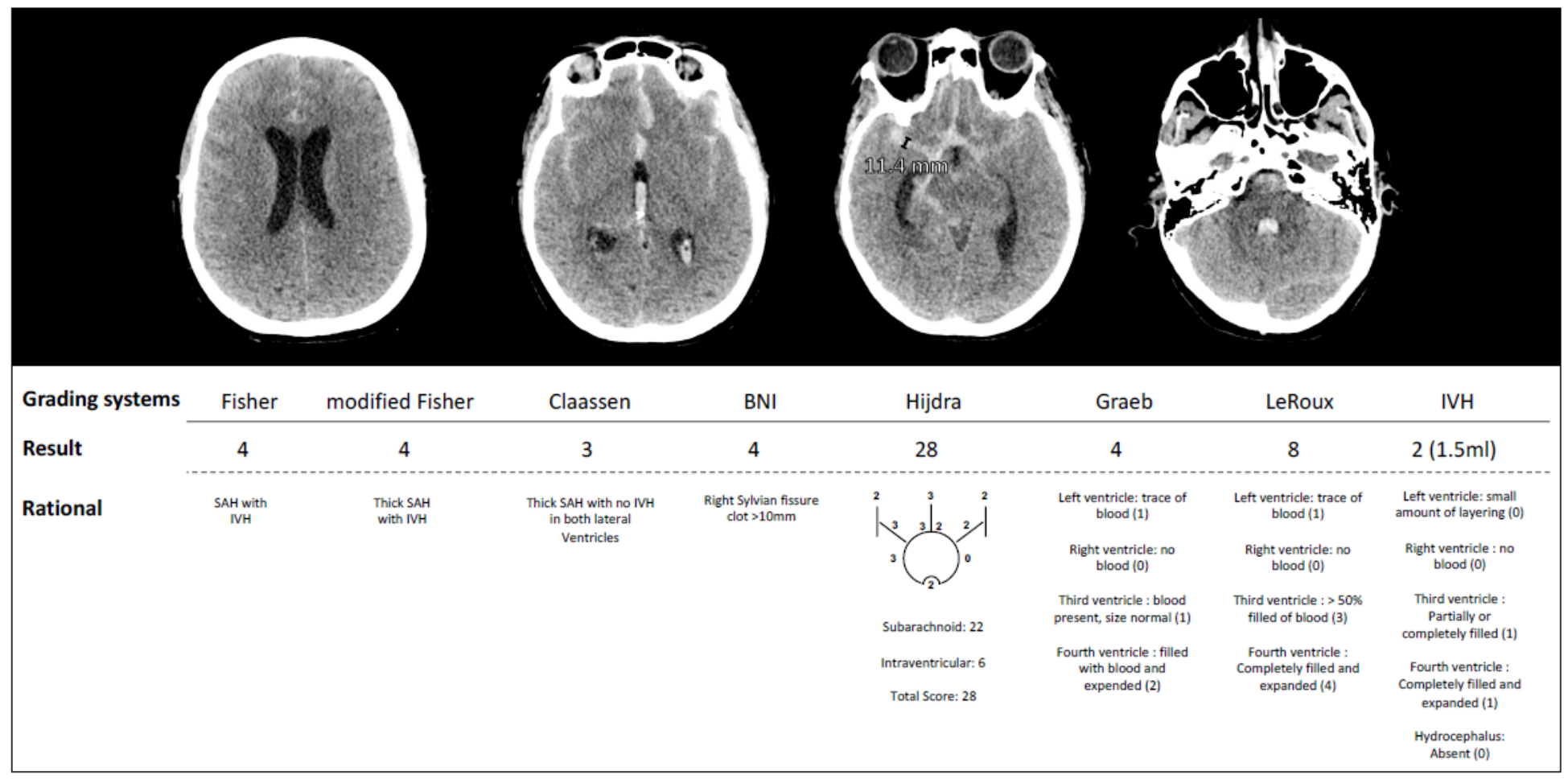

\section{Figure 1}

Illustration of the eight CT-scan based grading systems from patient 6 hours after subarachnoid haemorrhage from anterior communicating artery aneurysm. 


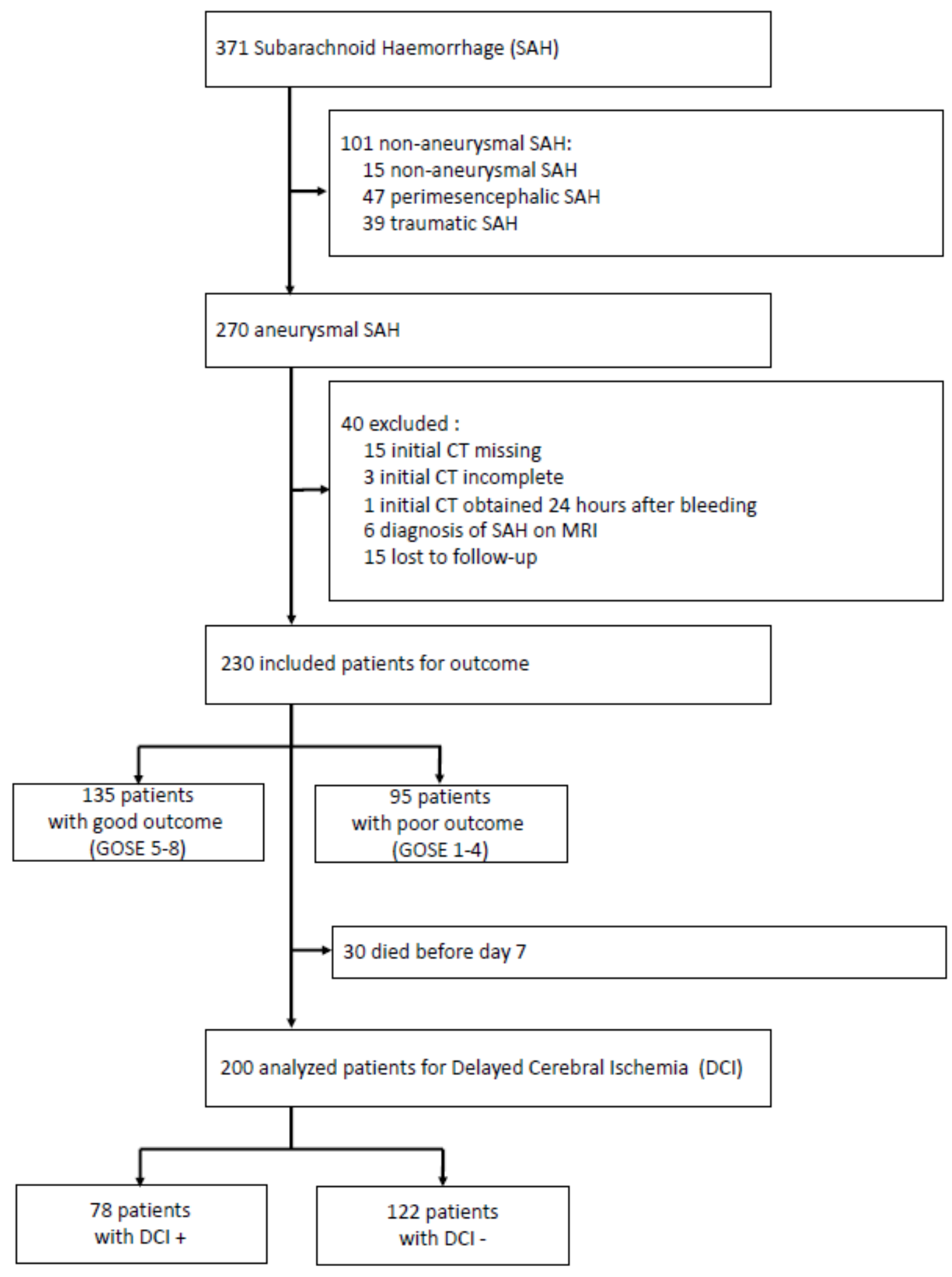

\section{Figure 2}

Flow of patients with subarachnoid haemorrhage (SAH) within this cohort. CT denotes computerized tomography; DCl, Delayed Cerebral Infarction; GOSE, Glasgow Outcome Scale Extended and MRI, Magnetic resonance imaging. 
A

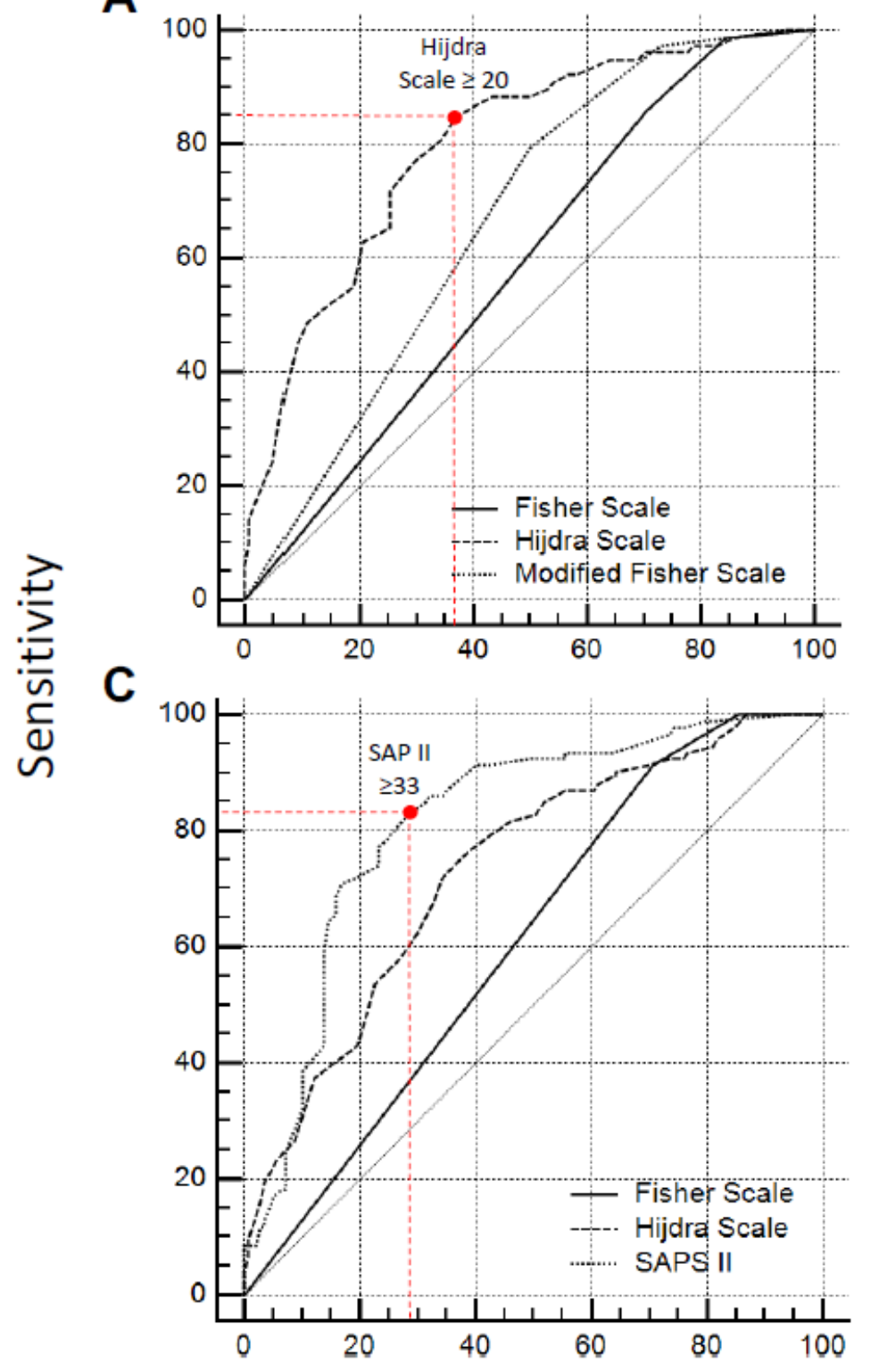

B

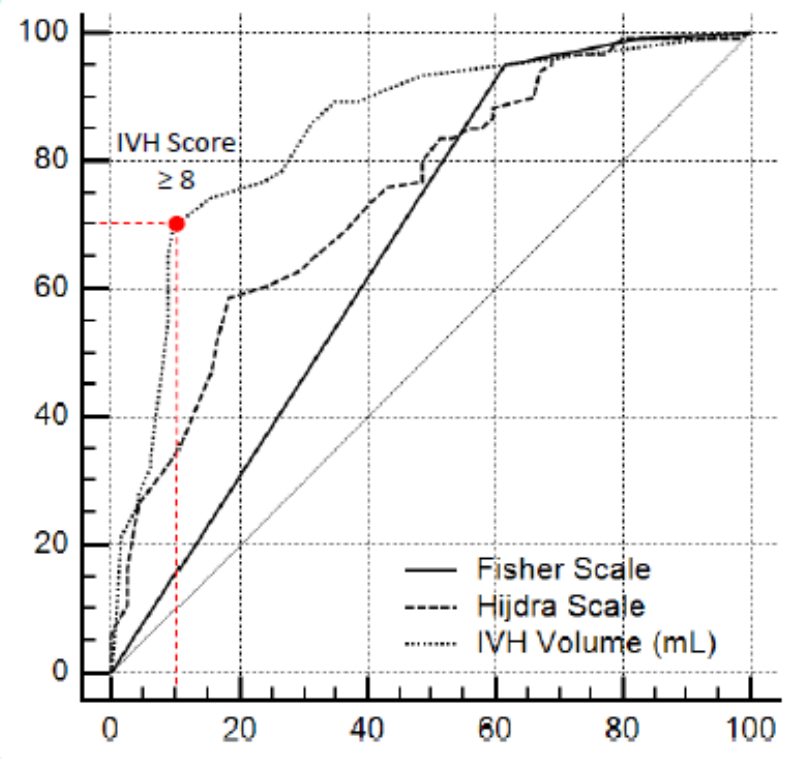

D

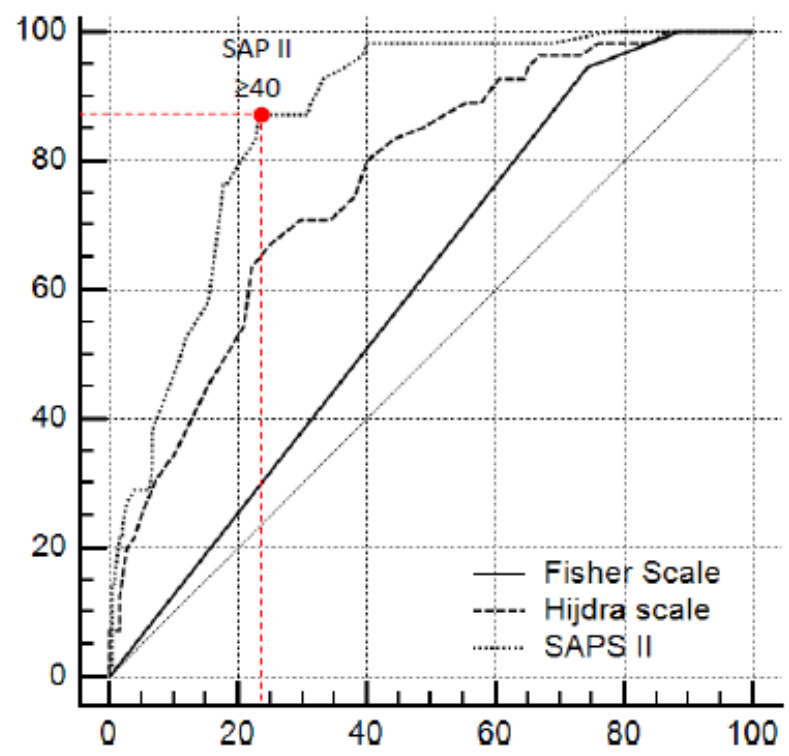

100-Specificity

\section{Figure 3}

ROC curves for the different qualitative, semi-quantitative, and quantitative measures used for determining the development of delayed cerebral infarction (A), poor outcome (B) death (C) and early hydrocephalus requiring external ventricular drain (D). 


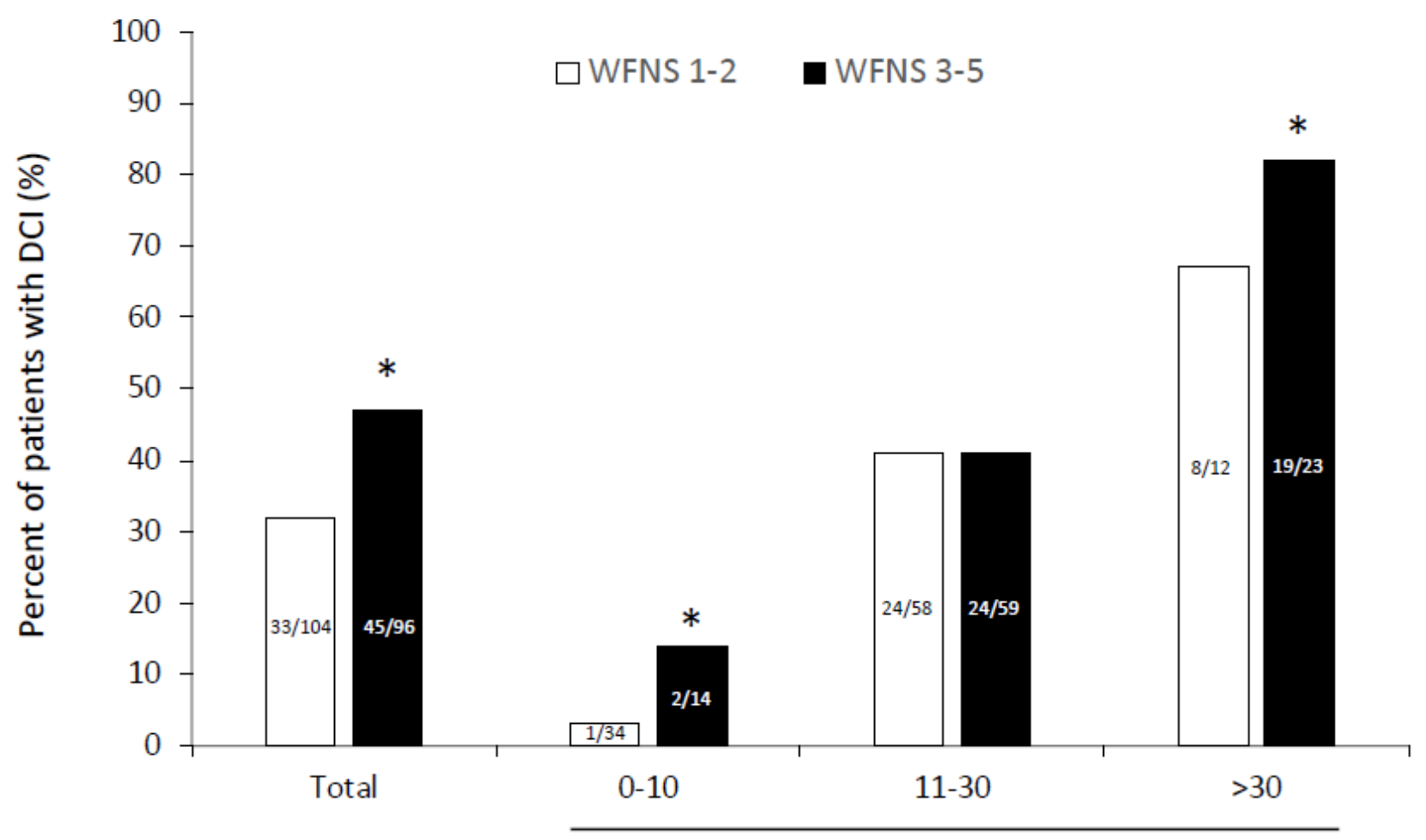

Hijdra Scale

Figure 4

Occurrence of DCl in low-severity aSAH (WFNS 1-2, white bar) and high-severity aSAH (WFNS 3-5, black bar) for the total population and grouped by Hijdra score $<10,10-30$, and $>30 .{ }^{*} p<0.05$, WFNS1-2 vs WFNS 3-5.

\section{Supplementary Files}

This is a list of supplementary files associated with this preprint. Click to download.

- Additionalfile1V2.docx 